\title{
TRADUÇÃO E INTERPRETAÇÃO DE LÍNGUA DE SINAIS NO CONTEXTO DA PÓS-GRADUAÇÃO: PROBLEMATIZANDO POSIÇÕES
}

\author{
Luiz Daniel Rodrigues Dinarte* \\ Universidade Federal do Rio Grande do Sul \\ Ângela Russo** \\ Universidade Federal do Rio Grande do Sul
}

\begin{abstract}
Resumo: Este artigo tem como objetivo, a partir de pesquisas sobre tradução e interpretação de língua de sinais, e, paralelamente, inserindo discussões com inspiração nas teorias contemporâneas afinadas ao conceito de “desconstrução" (DERRIDA, 2004, DERRIDA E ROUDINESCO, 2004, ARROJO, 1993), refletir sobre alguns aspectos relativos à definição do papel e das atribuições dos tradutores e intérpretes. Concebemos que a desconstrução não consiste em um método a ser aplicado sobre os fenômenos linguísticos e sociais, mas um conjunto de estratégias políticas que partem de uma coletividade de falantes que traduzem textos, e, portanto, se entregam à tarefa tradutória efetuando uma leitura que insere a língua de sinais na multiplicidade linguística acadêmica.
\end{abstract}

Palavras-chave: Tradução e Interpretação de língua de sinais. Pós-graduação. Desconstrução.

\footnotetext{
* Mestre em Educação pelo PPGEDU/UFRGS. Doutorando em Educação. Tradutor e Intérprete de Libras na UFRGS. Porto Alegre. Rio Grande do Sul. Brasil. E-mail: dionisio.z@gmail.com

** Mestre em Educação pelo PPGEDU/UFRGS. Tradutor e Intérprete de Libras na UFRGS. Porto Alegre. Rio Grande do Sul. Brasil. E-mail: alegnaossur@ gmail.com
} 


\title{
TRANSLATION AND INTERPRETATION OF SIGN LANGUAGE IN THE POSTGRADUATE CONTEXT: PROBLEMATIZING POSITIONS
}

\begin{abstract}
This article aims, based in sign language translation researches, and at the same time entering discussions with inspiration in contemporary theories on the concept of "deconstruction" (DERRIDA, 2004 DERRIDA e ROUDINESCO, 2004 ARROJO, 1993), to reflect on some aspects concerning to the definition of the role and duties of translators and interpreters. We conceive that deconstruction does not consist in a method to be applied on the linguistic and social phenomena, but a set of political strategies that comes from a speech community which translate texts, and thus put themselves in a translational task performing an act of reading that inserts sign language in the academic linguistic multiplicity.
\end{abstract}

Keywords: Translation and Interpretation of sign language. Postgraduation. Deconstruction.

\section{Introdução}

A conquista de direitos por parte dos sujeitos surdos é um fenômeno recente no nosso país, fato que proporcionou a visibilidade da atuação de profissionais tradutores e intérpretes de língua de sinais (TILS). No Brasil, as políticas de inclusão, principalmente no âmbito educacional, vêm dando destaque a essa figura como uma das condições de acesso dos surdos aos bens culturais. Uma consequência dessa nova demanda é a multiplicação, nas recentes décadas, de cursos de formação, visando qualificar a acessibilidade dos surdos nos espaços sociais que estes passam a frequentar, outra consequência é a mudança das relações profissionais entre surdos e TILS. Houve uma significativa alteração nas relações entre TILS e a comunidade surda. O ensino superior, no contexto brasileiro, tem se constituído como um espaço, onde tal alteração é evidenciada, destacando-se pelo fato de a universidade ser uma via de ascensão social para os surdos ao mesmo tempo em que impõe a necessidade de uma formação mais profícua dos TILS que atuam neste nível de ensino. Esse duplo movimento de empo- 
deramento dos surdos e da demanda por uma formação específica e adequada delimitação do papel desses profissionais nos parece remeter a mais uma dimensão do movimento de inclusão social dos surdos: o caminho, necessário e difícil, a ser trilhado no sentido de compreender e respeitar o TILS como um trabalhador, como um intelectual que deve dispor de tanta autonomia quanto qualquer tradutor ou intérprete de línguas cujo status já é estabelecido. Enfatizamos que, neste processo, a pós-graduação tem sido um espaço que guarda especificidades, onde a presença do TILS $^{1}$ se aproxima não apenas da atuação em sala de aula, para mediar a comunicação entre professor e aluno, mas também da pesquisa, da produção de conhecimento por parte de pesquisadores surdos e ouvintes.

Partindo dessas reflexões é que esse artigo se propõe, a partir de pesquisas sobre tradução e interpretação de língua de sinais, e, paralelamente, inserindo discussões com inspiração nas teorias contemporâneas afinadas ao conceito de "desconstrução" (DERRIDA, 2004; DERRIDA; ROUDINESCO, 2004; ARROJO, 1993), refletir sobre alguns aspectos relativos à definição do papel e das atribuições dos TILS na pós graduação. Concebemos que a desconstrução não consiste em um método a ser aplicado sobre os fenômenos linguísticos e sociais, mas um conjunto de estratégias políticas que partem de uma coletividade de falantes que traduzem textos, e, portanto, se entregam à tarefa tradutória efetuando uma leitura que insere a língua de sinais na multiplicidade linguística acadêmica. Elencamos exemplos, a partir de nossas vivências na posição de TILS na pós graduação, que problematizam as negociações linguísticas entre surdos falantes da Libras e nós, enquanto profissionais e pesquisadores da área. Uma amostra dessas negociações seria a criação de sinais para conceitos específicos de disciplinas no ensino superior, com foco nos cursos de pós-graduação. Tais pontos não poderiam ser identificados sem que nós, como TILS, não estivéssemos envolvidos diretamente nesses processos. Portanto, cabe destacar que além de atuarmos como intérpretes em sala de aula em disciplinas, principalmente de pós-graduação (UFRGS - Universidade Federal do Rio Grande do Sul) há mais de 
uma década, e como tradutores de textos dos surdos que realizam suas formações em nível de Mestrado e Doutorado, também desenvolvemos pesquisas que buscam compreender as questões que cercam a tradução e a interpretação de/para Libras. O que percebemos é que, no contexto da atuação na universidade, são muitos os discursos que atravessam a construção de um perfil profissional, e o sentido da universidade é, para os surdos, o de tomar a palavra socialmente. Tanto os surdos, cuja ascensão social recente agrega um teor político e de contestação à sua presença na universidade, quanto os TILS, que trazem, de maneira semelhante, vieses políticos que produzem efeitos em sua consolidação profissional, aparentam certa dificuldade em construir uma relação de trabalho em que as marcas históricas não sejam um entrave à consolidação da atuação dos TILS. Talvez não seja mesmo o caso de eliminar as marcas históricas dessa relação, mas de nelas imprimir um movimento, falar dessas marcas, dizê-las do ponto de vista de uma necessária convivência e de uma urgente tradução a ser realizada pelas coletividades sinalizantes.

Entendemos que esse atravessamento das marcas históricas, nos termos da desconstrução, que se instaura nas manifestações políticas, discursivas e institucionais, e mesmo em algumas posições supostamente teóricas assumidas por pesquisadores que abordam a língua de sinais e a cultura surda, são resultado de um jogo de substituições, no qual os valores significantes são realocados e acomodados à medida em que a nossas atividades profissionais e o lugar social dos surdos se tornam objeto de visada teórica e institucional. A universidade se coloca como um lugar de destaque nesse processo uma vez que não é um lugar de procedimentos mecânicos, como diria Derrida (1999), a universidade não é uma colmeia, e sua razão de ser foi rapidamente absorvida pelas lutas dos surdos. Dizemos que a universidade foi absorvida, uma vez que entendemos que a política das pessoas surdas tem como característica uma capacidade de mobilização bastante potente e que tem tido crescente visibilidade em relação aos espaços e os discursos, nisso, os surdos se apropriam dos espaços que lhes são de direito. Com 
isso queremos dizer que há uma tendência crescente no sentido de tornar a universidade um dispositivo de racionalização das pautas surdas, no sentido de uma "certa relação essencial da razão com o ser (DERRIDA, 1999, p. 131). Mas, argumentamos, apesar da legítima questão ontológica que os surdos deslocam e realocam no âmbito dos saberes sobre os diferentes, as diferenças e a Diferença, é preciso refletir sobre os equívocos e excessos que tal racionalidade enseja. Dizer que a língua é "propriedade" de um povo ou grupo de falantes é, por exemplo, enclausurar a própria língua, marcando posições de interesses antagônicos. No caso das línguas de sinais, as posições se definiriam pela dicotomia surdos/TILS estrangeiros. Entendemos que se há antagonismos, não é no sentido de propriedade da língua ou da cultura, a disputa, no nosso entender, se dá no âmbito da própria língua, seu engrandecimento, sua movimentação tradutória diante de textos científicos e filosóficos. Aí está, no nosso entender, a grande força política a ser desenvolvida pelas pessoas surdas na universidade.

Acreditamos que as contradições e indecisões produzidas ao longo da última metade do século XX no campo político e educacional voltado para as pessoas surdas chega à universidade, local de ostensivo avanço do protagonismo social dos surdos, na forma de enfrentamentos linguísticos, embora tais enfretamentos não determinem posições ideais, isto é, não há lados opostos cuja assimetria social requeira uma reconstrução da língua. A reconstrução se dá no sentido de fazer com que a língua entre na ordem do dia, ou seja, que passe a compor a multiplicidade de vozes que a universidade cada vez mais se propõe a abrigar. A pós-graduação se insere, nesse contexto, como a ponta mais profícua desse "aparecimento" social das pessoas surdas, uma vez que é nesse nível de formação que os próprios surdos investigam, em muitas frentes de pesquisa e perspectivas teóricas, as temáticas que são caras à consolidação da língua de sinais e cultura surda como domínios de saber científico. Mas eles o fazem junto aos TILS. Para os TILS que atuam na pós-graduação, fica evidente o trabalho conjunto que deve ser desenvolvido junto aos surdos, no sentido de colocar em circulação 
discussões que ainda não possuem referências empíricas anteriores na prática de interpretação e tradução. É importante frisar que a atividade dos TILS não se restringe à interpretação simultânea em sala de aula. Tais profissionais, em consequência de boa parte dos surdos apresentar um histórico acadêmico de insuficiente aquisição da língua portuguesa, também atuam realizando a tradução de dissertações, teses e demais gêneros de textos científicos. Isso é amplamente experienciado por nós junto aos surdos que frequentam cursos de mestrado e doutorado: nesse sentido, é preciso realizar um trabalho de investigação e estudo de teorias filosóficas, elaboração de sinais (mesmo que provisórios), para tratar de conceitos, realizar filmagens desses sinais, registrar em língua portuguesa aquilo que os surdos desenvolvem em língua de sinais. Entretanto, nem sempre os intérpretes possuíram parâmetros para realizar a interpretação em sala de aula ou a tradução para o português escrito daquilo que os surdos depreendiam de suas leituras dos textos e de suas práticas investigativas. Foi preciso que os próprios TILS dessem prosseguimento às suas formações para que esse trabalho pudesse ser aprimorado. Afirmamos que esta prática realizada junto aos surdos, por vezes, gera conflitos, tornando evidentes discursos advindos de um contexto político e social mais amplo que produz interferências significativas no trabalho de tradução e de interpretação, discursos carregados de preconceitos em relação à definição do trabalho dos TILS.

Não entendemos tais enfrentamentos como polos dicotômicos no sentido de conceber os surdos e os TILS como portadores de ideais distintos e ocupantes de lugares sociais opostos. Surdos e ouvintes participam, com atravessamentos institucionais distintos, de processos de inclusão social que visam à diminuição de barreiras de comunicação, nisso, não são senão aliados em um fenômeno amplo de mudança social. Isso é, todos, surdos e ouvintes, estão traduzindo textos, interpretando, produzindo sentidos, a partir de informações que, por adventos históricos de opressão e exclusão social, deixaram de circular nas comunidades surdas por muito tempo. Neste momento de acelerada mudança, os TILS se inserem 
como aqueles que, passando de parceiros de luta a profissionais localizados institucionalmente, assumem a tarefa de traduzir e de interpretar, isto é, passam a ser entendidos como trabalhadores, responsáveis por uma parte de um projeto maior de emancipação dos surdos. Nesta realocação, os discursos sobre essa nova posição se confundem, se misturam, atribuindo aos TILS, muitas vezes, características que, ou não condizem com a definição destes como profissionais, ou, ainda, buscam interditar suas funções a partir de um discurso de militância ou fundamentado em ideias que estariam fora do escopo conceitual necessário, no nosso entendimento, ao traçado de um perfil profissional.

Diante dessa configuração, desse "contrato" dos profissionais para com os surdos, trazemos dois exemplos, sendo um já clássico, consistindo em uma afirmação sobre a prática profissional já observada por praticamente a totalidade dos TILS, e outro que se relaciona ao nosso objetivo principal neste artigo. Tais exemplos servirão para dar forma aos embates que nos mobilizaram a escrever. Primeiro: é recorrente a afirmação de que a neutralidade deve ser buscada pelos TILS. Vemos aí um necessário deslocamento no sentido de pensar em que medida a neutralidade é possível e/ou desejada. A afirmação é que a função do intérprete seria a de "só" interpretar e a do tradutor é também "só" traduzir. Entendemos que o contrato que vem se delineando como uma relação profissional também pode ser deslocado no sentido daquilo que Derrida (2002) entende a partir do engajamento do tradutor em relação ao texto, ou melhor, em relação àquilo que o texto solicita como operação tradutória. Novamente percebemos que o que conduz a tradução não é nenhuma propriedade em relação à língua, nenhuma autoridade moral em relação ao texto, mas, ao contrário, um movimento essencialmente textual que engaja os tradutores. Nesse sentido é que não podemos ver os TILS e surdos em lados opostos, um lado dos profissionais e outro dos receptores. A neutralidade, diante disso, não é possível, já que o engajamento na tradução é provocado pelos textos que solicitam a tarefa tradutória. De outra parte, a tradução como mediação não nos parece uma definição 
adequada, já que o sentido dos textos não é restituído em uma língua e outra; há um duplo movimento entre textos, um contorno a ser criado na língua de sinais no sentido de atualizar a criação realizada na língua fonte.

Entendemos que a afirmação de que o TILS "só" traduz ou "só" interpreta é uma ilusão mecanicista, no sentido de decalcar a neutralidade da mediação linguística. Subjacente a isso, uma concepção de tradução como transmissão, como transporte de sentido, na qual haveria, na perspectiva dos usuários do serviço de tradução e interpretação, isenção de envolvimento subjetivo, um tipo de despersonalização. Tal ausência não reflete o trabalho de interpretação, menos ainda de tradução, nos parece infundada a ideia de que o TILS deve se limitar a uma mediação comunicacional entre os "reais" atores da cena comunicativa. Disso se depreende ainda a concepção de leitura e de texto, fortemente calcados no senso comum, no qual o tradutor é entendido como aquele que busca, de forma neutra e isenta de subjetividade, a intenção original do texto a traduzir.

Segundo exemplo: o usuário nativo seria o único "autorizado" a tomar decisões como "criar" sinais a partir do entendimento de conceitos científicos; batizar pessoas, lugares; perceber e definir padrões estéticos na língua de sinais, etc. Tudo isso sob a alegação de que o surdo é o "dono" da sua própria língua e, portanto, é o mais habilitado a tomar tais decisões. A partir dessa ideia, a tradução seria uma tarefa mecânica, subordinada às definições dos surdos como aqueles que, por serem os supostos proprietários da língua, seriam capazes de estabelecer a forma "correta" de traduzir, agindo como críticos que teriam a responsabilidade de "guiar" ou, ainda, "balizar" o trabalho dos TILS.

Os exemplos acima serão discutidos e aprofundados nas próximas seções, bastando, por ora, que tenhamos em mente o tipo de caminho aqui proposto: são pistas sutis, corriqueiras, que por vezes ganham um estatuto de verdade nas falas e em algumas escritas de pesquisadores da área de Libras, que dão a ver efeitos de discursos que se cruzam com outras práticas discursivas. Veja-se: não se trata de um julgamento sobre os equívocos, mas dos desacordos 
entre as intenções políticas dos surdos e as intenções profissionais dos TILS diante do necessário alargamento conceitual ensejado pelas concepções contemporâneas sobre a atividade tradutória. Por um lado, se deseja construir um perfil profissional, com seus parâmetros de atuação, mas, por outro, continua-se "bombardeando" a atuação dos TILS com discursos (leia-se, efeitos de discursos) advindos de outras propostas de atuação, já vivenciadas no passado (a ajuda, a caridade), ou, ainda, presentes em outras esferas de atuação social dos surdos (o surdo autônomo é, obviamente, responsável por sua vida, por suas escolhas, mas, definitivamente, não é "dono" de uma língua, ninguém "possui" um sistema linguístico, senão metaforicamente).

\section{O TILS na universidade}

A década de 2000 foi um marco para o reconhecimento da Libras como língua utilizada pelas pessoas surdas brasileiras, e, com isso, houve um reconhecimento do surdo como sujeito cultural, político, que deve ter sua autonomia respeitada e seus direitos pensados a partir de sua diferença. $\mathrm{O}$ entendimento da diferença como direito levou as comunidades surdas a se organizarem na luta por direitos sociais, principalmente em relação ao emprego e à educação. São estas duas dimensões que mais vem ganhando destaque no contexto brasileiro quando se tematiza a pessoa surda e a língua de sinais. Em relação ao contexto educacional, meio onde a figura do TILS é mais solicitada, pode-se dizer que a maioria das políticas referentes às pessoas surdas tematizam, de uma forma ou de outra, a necessidade da presença desse profissional.

O TILS está em um processo de consolidação do seu papel na educação de surdos, delineando sua atuação, seu perfil profissional ainda não é bastante claro nas escolas e universidades e cujas características ainda está em construção do ponto de vista discursivo (RUSSO, 2009). Ou seja, a atuação ainda carece de descrições, parâmetros e regulações para que os próprios profissionais con- 
sigam perceber e selecionar suas atribuições. Embora a profissão tenha sido regulamentada a partir da Lei 12.319/2010, ainda são muitas as carências no sentido de ampliar as discussões sobre ética, parâmetros curriculares de cursos de formação, redefinições entre cargo e função ${ }^{2}$, etc. É preciso, ainda, levar em conta que algumas universidades estão mais adiantadas em relação ao acesso de alunos surdos, seja por terem iniciado esse processo há mais tempo ou pelo fato de a acessibilidade ser uma política institucional mais consolidada. Existem instituições de ensino superior que possuem dezenas de alunos surdos, entre graduação e pós-graduação, ao passo que, em outras, existem TILS contratados, mas não há sequer um aluno surdo matriculado.

Nos últimos 10 anos, a partir do Decreto 5626/2005, viu-se um crescimento exponencial do número de surdos que frequentam a universidade. Conforme a lei:

Art. 14. As instituições federais de ensino devem garantir, obrigatoriamente, às pessoas surdas acesso à comunicação, à informação e à educação nos processos seletivos, nas atividades e nos conteúdos curriculares desenvolvidos em todos os níveis, etapas e modalidades de educação, desde a educação infantil até à superior. (BRASIL, 2005).

O referido decreto subsidiou a conquista de um espaço que outrora foi pouco frequentado por pessoas surdas. Muitos surdos, que tiveram acesso aos cursos universitários antes da lei, relatam que dependiam da ajuda dos professores e colegas, ou intérpretes voluntários que se dispusessem a acompanha-los em sala de aula. Quando não havia intérprete, isto é, na maioria das vezes, os surdos criavam estratégias, construindo uma rede de apoio em torno de si para que sua formação fosse possível.

Após a lei, como já percebemos desde o início deste artigo, foram outros os problemas encontrados, principalmente em relação à definição do papel profissional do TILS que, deixando de ser 
alguém que dedicava seu tempo livre em ajudar as pessoas surdas, fossem parentes ou amigos, agora passam a ser profissionais, recebendo salário, mantendo uma ética profissional, devendo ter uma formação específica. Reichert (2012) percebe esta mudança de paradigma na atuação e delimitação do perfil dos profissionais TILS como um processo de negociação cultural, a partir do qual a figura caritativa, dando lugar ao TILS trabalhador, ainda produz relações conflituosas e com viés emocional e de cunho pessoal. A partir desse complicado jogo de relações entre TILS e surdos, alguns pesquisadores, atentos para a necessidade de explicitar conflitos e amenizar as interferências na definição do "novo" papel que deve ser assumido pelos intérpretes, tentaram categorizar, de maneira não definitiva ou absoluta, as características e modelos das atuações, desde as mais tradicionais às mais adequadas às demandas atuais.

Pereira (2008), ao descrever alguns modelos profissionais, afirma a existência de um Modelo aliado, onde haveria, entre profissional e usuário, um compartilhamento de poder, uma parceria que tem como meta amenizar as barreiras enfrentadas pelas pessoas surdas. Percebe-se que esse modelo mantém um viés político, característica comum a muitos TILS. É fácil perceber que há uma diferença considerável entre tradutores e intérpretes de língua de sinais e de línguas orais, e esta diferença advém principalmente do tipo de aproximação destes com os usuários de seus serviços. Os TILS são herdeiros de um histórico de atuação baseada na caridade, de ajuda aos surdos, de informalidade. Não por acaso, grande parte dos profissionais provém de comunidades religiosas. Mesmo se afastando de um modelo de atuação caritativo, ainda permanece um tipo de compromisso social com os surdos. Além do compromisso social, há também um viés pedagógico que acompanha o histórico da profissão. A tradução e a interpretação, nesse contexto, são realizadas em junto a uma comunidade excluída por sua diferença linguística. A língua de sinais possui uma modalidade de produção e recepção que dificulta o acesso a informações, conceitos, artefatos artísticos e culturais da maioria ouvinte, mídias, etc. Prover o acesso a esses bens culturais, ou seja, traduzir e/ou 
interpretar textos escritos e orais para a língua de sinais requer a compreensão do contexto histórico e social no qual essa língua se localiza. Entendemos, todavia, que exatamente em decorrência da pouca circulação de produtos culturais nessa língua é que há uma grande potência criadora em seu meio, e o sentido pedagógico que evocamos não é senão o de uma pedagogia da criação e da tradução como força inventiva.

Coincidência ou não, foi o campo da Educação que iniciou os primeiros debates sobre a questão da tradução e da interpretação para surdos. Aguiar $(2010,2013)$ aponta, no fenômeno de delimitação do perfil dos TILS no Brasil, através de um levantamento do estado da arte das pesquisas de mestrado e doutorado, que houve certa indecisão acerca do lugar de atuação e formação desse profissional. Percebe-se, ainda, que os cursos de tradução e de interpretação de Libras em nível de pós-graduação (Especialização), assim como os cursos de extensão, possuem uma forte ligação com o campo da Educação. Muitas das temáticas dos cursos tratam de assuntos ligados à Educação e muitos dos autores estudados são oriundos desse campo. Observamos que a formação e atuação dos TILS têm sido perpassadas por discussões do campo da Educação, porém, mais recentemente, principalmente após a criação dos cursos de Letras-Libras, é o campo da Linguística e os Estudos da Tradução que ganham destaque.

Ainda é possível perceber que a Educação continua sendo um espaço importante na formação dos TILS e mesmo dos surdos, que tiveram neste campo de saber uma espécie de "abertura" para a legitimação de lutas e discussões sobre a escolarização bilíngue. Pensamos que este histórico acadêmico que constituiu as bases para as conquistas sociais que temos atualmente continua produzindo efeitos sobre a atuação profissional. Não consideramos este histórico algo a ser superado, mas delimitado e, com a intenção de definir o lugar e as atribuições do TILS, é necessário que os campos de investigação contribuam com a formação, ao invés de disputar um lugar de destaque. Nosso argumento é que, apesar de a Linguística e de os Estudos da Tradução serem nomeadamente as abordagens 
nas quais os TILS encontram seu espaço de formação de direito, há um desdobramento de fato no que tange à reflexão filosófica, ainda incipiente em nosso meio.

Muitas vezes, o escopo conceitual dessas duas áreas de conhecimento é ignorado em função de discursos outros. É preciso evitar que os discursos se sobreponham, interditando e, o que ocorre muitas vezes, impossibilitando a atuação dos profissionais. É possível observar que a atuação do TILS não pode ser abordada sem levar em conta fenômenos sociais, para além de uma abordagem da língua como sistema absoluto, e não é admissível que os profissionais sejam confinados por discursos políticos, como a afirmação, por exemplo, de que os surdos seriam os "proprietários" da língua de sinais e por isso os TILS devem aguardar que eles decidam quais são os sinais que devem ser utilizados ou não.

Nossa experiência se dá principalmente em um curso de pósgraduação em Educação, onde estes problemas têm ganhado mais destaque à medida que os alunos/pesquisadores aprofundam suas leituras das teorias e as relacionam com seus objetos de investigação. Uma consequência disso é a maneira como é entendida a atuação do TILS. Quando argumentamos que o contexto da pósgraduação possui especificidades, é no sentido de ser o contexto pesquisa e ensino onde o campo de investigação relativo às temáticas que envolvem a Libras ganha forma e se distingue como saber científico. É nos cursos de mestrado e doutorado que se vê "nascer" os assuntos que, posteriormente, se configuram como o próprio saber sobre a língua de sinais. É muito diferente da tradução e da interpretação em contexto escolar ou mesmo em cursos de graduação, onde os conteúdos curriculares, já consolidados em seus respectivos campos de saber, são recebidos pelos alunos estando localizados em paradigmas e perspectivas teóricas e devem ser estudados pelos alunos surdos segundo estes parâmetros. Não se trata de um julgamento sobre o nível de aprofundamento do trabalho de tradução e de interpretação em um e outro tipo atuação, mas de uma diferença sobre a aproximação e apropriação de alunos e TILS em relação aos saberes. 


\section{Comunidade interpretativa: a desconstrução e os equívocos conceituais}

Stanley Fish (1980) define uma comunidade interpretativa (interpretive community) como um conjunto de possibilidades de leitura segundo as experiências interpretativas de um grupo, que não podem prescindir das suas condições culturais, ou seja, daquilo que seus integrantes podem depreender de um texto segundo suas bagagens históricas. Mesmo não sendo um teórico da desconstrução, entendemos que sua concepção de interpretação se afina ao que defendemos como uma atividade tradutória que é mais coletiva do que pertencente a um sujeito. Nesse sentido, um texto não poderia ser entendido como portador de um sentido original, estável, fonte da qual os leitores resgatariam um significado verdadeiro e último. Arrojo (1993), ao perguntar a que são fiéis os tradutores e críticos de tradução, está questionando se o crítico de tradução, ao apontar "erros" e "acertos" de um processo tradutório, "estará considerando o mesmo original que o tradutor?" (ARROJO, 1993, p.16, grifo nosso). Grifamos a palavra "original" pelo fato de esta autora estar falando desde uma perspectiva de desconstrução, uma perspectiva teórica que não entende que a origem é algo passível de desvelamento, de captura por parte do leitor e/ou tradutor. A partir da suspensão do entendimento teológico de origem e da sugestão de que uma comunidade interpretativa estabelece padrões de leitura não a partir de um significado transcendental, mas de um processo comunicacional coletivo, podemos perceber que a tradução não pode ser vista senão como um trabalho altamente atrelado ao contexto histórico e às experiências culturais dos leitores.

Para tal perspectiva de desconstrução, haveria uma tradição logocêntrica, um entendimento da linguagem como portadora de um sentido último e verdadeiro, um "significado transcendental", perspectiva a ser desconstruída através do entendimento do texto não como fonte de uma leitura verdadeira, mas como abertura para várias interpretações. No que se refere aos estudos que abordam a tradução, o entendimento de "texto original", quando assumida 
a perspectiva da desconstrução, deve ser colocado sob análise cuidadosa, para evitar as armadilhas do pensamento tradicional logocêntrico - a saber, o entendimento do senso comum sobre tradução em termos de fidelidade, respeito ao sentido original, presença do sentido à linguagem, etc., seria aquilo que deveria orientar a leitura do intérprete/tradutor/desconstrutor. Ler, nesse sentido, seria, na tradição intelectual do Ocidente,

em última análise, uma atividade que propõe a "proteção" dos significados originalmente depositados no texto por seu autor. Embutida nessa concepção de leitura, delineia-se a concepção de tradução que tem orientado sua teoria e prática: traduzir é transportar, é transferir, de forma "protetora" os significados que se imaginam estáveis de um texto para outro e de uma língua para outra. (ARROJO, 1993, p. 16).

Para esta concepção de leitura, texto e tradução, ao leitor, e, consequentemente, ao tradutor, caberia simplesmente a tarefa de descobrir as "reais" intenções do autor, sendo este o "detentor" do significado do texto. Ao contrapor esse modelo de entendimento, a autora destaca a importância de diversos pensadores contemporâneos que, cada um ao seu modo, tentam inverter o paradigma do logocentrismo e compreendem a linguagem, a leitura e o texto como processos infinitos de interpretação. A influência mais importante nesses empreendimentos é, sem dúvida, do filósofo alemão Friedrich Nietzsche (2009), que exerce influência sobre vários autores contemporâneos que de alguma forma abordaram a linguagem.

Com Michel Foucault (1999), em suas pesquisas iniciais, verificou-se o "surgimento" de objetos de saber a partir das formações discursivas. O processo de aparecimento do homem como preocupação teórica, por exemplo, é abordado pelo filósofo com a perspectiva de invenção, não sendo possível, numa análise das assertivas científicas e filosóficas entre o Renascimento e a Modernidade, concebê-lo senão a partir da descontinuidade (CANDIOTTO, 2009). 
Por outro lado, Roland Barthes (2004), destitui o lugar do Autor como o detentor de todas possibilidades interpretativas, radicalizando tal destituição ao afirmar que é necessário, ao escrever, "atingir aquele ponto em que só a linguagem atua, 'performa', e não 'eu'” (2004, p. 59). De maneira especial e cara aos Estudos da Tradução, Jacques Derrida (2004), aquele que cunhou o termo desconstrução como uma operação interpretativa sobre os textos, trouxe contribuições decisivas para este campo de investigação. Subjacente ao conceito de desconstrução, está, marcadamente, a ideia nietzschiana de metaforização. A isto corresponde a ideia de que a linguagem não é capaz de capturar a "essência" das coisas, nem o sentido verdadeiro dos fenômenos, mas é entendida como um processo de substituição de uma sensação momentânea, histórica e datada, por um som, por um signo que, mesmo que provisoriamente, pudesse arcar com a dívida imposta pela significação. Nesse sentido, Nietzsche concebeu a própria verdade como uma ficção.

O homem, realizando sistematicamente tais processos de metaforização, "inventa" verdades, de maneira, segundo o entendimento nietzschiano, a dissimular o seu desejo de poder. É essa dissimulação que torna o homem um inventor de suas verdades, ou seja, um inventor de significados. Não há, portanto, significado primeiro a ser resgatado em um processo interpretativo, uma vez que o sentido se constitui como processo infinito de interpretações. Nenhum leitor, nem mesmo o autor de um texto, é o detentor da verdadeira intenção - nisso, o "real" querer-dizer de um texto se perde, perfilado nas perspectivas das quais se lança uma leitura/interpretação. O leitor se situa ao lado da criação e da produção, e não, como se imagina no senso comum relativo ao trabalho de tradução e interpretação, da conservação e da proteção (do significado). O significado, portanto, não é aqui entendido como estável, pois este

se delineia e se cria, a partir de um ato de interpretação, sempre provisória e temporariamente, com base na ideolo- 
gia, nos padrões estéticos, éticos e morais, nas circunstâncias históricas e na psicologia que constituem a comunidade sociocultural. (ARROJO, 1993, p. 19).

$\mathrm{Na}$ esteira desse pensamento, podemos afirmar que os tradutores, os intérpretes, os surdos e os demais falantes das línguas de sinais formam, no seio de suas vivências linguageiras, "comunidades interpretativas", porém, ao invés da metaforização ocorrer entre sentido e som, são sinais, é matéria gestual que se insere no processo de ficcionalização da realidade. Em tal concepção de $c o$ munidade (conceito caro à agenda política surda contemporânea), não se entende o trabalho de interpretação e tradução como transmissão ou transporte de sentido, muito menos se entende que sobre alguns recai a responsabilidade em dar conta dos processos interpretativos. Muito menos se entende que os falantes, nativos ou não, de uma língua, detenham, por direito ou por decreto, a autoridade de decidir quais parâmetros lexicais, sintáticos ou estéticos deverão prevalecer nos textos traduzidos. É o intencionar da criação dos textos que regem o trabalho interpretativo. Traduzir um texto é sempre uma problematização da língua meta segundo a intenção da língua fonte, atividade coletiva, dividida entre os leitores/ tradutores - estes, os autorizados a criar e restabelecer, conforme aquilo que interpretam, o sentido de um texto. Sendo a língua meta sempre situada histórica e socialmente, sempre ocupando um lugar cultural, e diante do fato de que a intenção criativa do texto fonte não determina o processo tradutório, não há uma axiomática, nem verticalidade, que force o texto de chegada a se comportar de uma forma preestabelecida, não há a menor possibilidade de interditar aos tradutores e intérpretes a participação em um processo criativo exatamente pelo fato de que eles dividem a operação tradutora com o público. Como já havia afirmado Benjamin (2011), a tradução, assim como qualquer obra de arte, não deve ser realizada com vistas a um público, pelo motivo de que é com vistas ao texto original como força criadora que a arte deve se voltar. Porém, entendemos que são as condições históricas, o horizonte de leituras possíveis 
de um grupo de receptores (no qual se incluem também os próprios tradutores) que condicionam coletivamente uma tradução.

O "processo criativo" a que nos referimos ocorre, quando se trata da língua de sinais, no âmbito de uma coletividade que abriga os sinalizadores, não importando a condição auditiva de cada um. $\mathrm{E}$, não havendo exatamente um locus privilegiado em que uma comunidade interpretativa, de leitores, tradutores e intérpretes, desenvolva suas aptidões de linguagem, entende-se que tal atividade se desenvolve no seio de muitas experiências de linguagem. Mas há, sem dúvida, lugares onde tais processos se permitam observar mais detalhadamente. Nossa afirmação de que existem interferências e interdições no processo tradutório vivido pelos TILS na pósgraduação se relaciona ao fato de que neste espaço, pela institucionalização do trabalho de tradução e interpretação, isso se delimita com maior amplitude de observação, há mais momentos de registro de tal atividade. E não é por acaso que os meios acadêmicos proporcionam as condições para que esses fenômenos se tornem visíveis. É preciso lembrar que é nas universidades, especialmente nos meios em que os surdos e os próprios TILS assumem autoria nas pesquisas, que o saber sobre a língua de sinais é sistematizado, trazendo à luz da ciência aquilo que jazia no senso comum. É neste espaço que a língua de sinais se faz presente em discussões que até então não passavam pelo seu crivo. A academia funciona como um dos espaços em que se amplia o escopo do que é tratado nessa língua. Os TILS fazem parte desse processo, compondo a comunidade interpretativa junto às pessoas surdas. Não é apenas o tradutor e o intérprete que realizam um trabalho de leitura e interpretação - toda a comunidade é autora nesse processo.

Mas, afinal, porque há interdição e interferências no trabalho dos TILS? Por qual motivo existem equívocos, como os mitos da "propriedade da língua" e da "neutralidade do TILS", que enviesam o saber sobre a língua e sobre os surdos, ganhando, muitas vezes, estatuto de verdade, enquanto seriam nada mais do que efeitos de uma trama interpretativa mais complexa do que a simples definição de papéis e posições? Porque o papel do TILS é reduzido 
e por que motivo lhe é negada a autoridade sobre seu próprio trabalho criador-produtor-tradutor? Acreditamos que os surdos sentem a necessidade de estabelecer pontos de convergência no discurso político e social em favor de seu reconhecimento e status - isso seria o sentido de empoderamento. Talvez, no desejo de produzir verdades e reconhecimento social (algo que consideramos totalmente legítimo e necessário), sejam produzidas assimetrias nas relações entre surdos e TILS, mesmo que os dois grupos, ao fim e ao cabo, tenham praticamente os mesmos objetivos (eliminação de barreiras comunicacionais, ampliação da acessibilidade, valorização da cultura e da língua dos surdos, etc.).

Enfim, afirmamos que todos, surdos usuários dos serviços de tradução e interpretação, TILS ouvintes e demais falantes da língua de sinais, estão engajados em um mesmo processo interpretativo. Todos se situam, num contexto acadêmico, na busca por enriquecimento do repertório linguístico ao fazer circular, nessa língua, informações, conceituações, através de perspectivas teóricas e gêneros textuais diversos.

\section{Expandir os horizontes}

Ao comparar a linguagem humana a uma velha cidade, Wittgenstein (1999) está declarando o caráter transicional e histórico dessa capacidade humana. O centro da cidade, conforme esta esclarecedora metáfora, é um lugar bastante desorganizado, composto por ruas entrecruzadas, vielas, prédios que não seguem padrões arquitetônicos. Seguem-se os subúrbios, as zonas novas, as construções modernizadas e visivelmente mais planejadas do que o centro da cidade. É fácil admitir que o centro corresponderia à linguagem cotidiana, com seus muitos atravessamentos e obscurecida pela cotidianidade, pela ausência de delimitações do que é ou não é parte do horizonte da produção de linguagem. De outra parte, as partes mais afastadas da cidade, segundo a comparação realizada pelo filósofo austríaco, consistiriam nas planificações da 
linguagem efetuadas pelas ciências. Química, Física, Matemática e Biologia seriam exemplos de uso ordenado da linguagem, segundo jogos determinados pelo uso criterioso das palavras que designam fenômenos específicos.

Não poderíamos deixar de mencionar a comparação acima, uma vez que ela traz à tona um olhar sobre o fenômeno da linguagem que atualiza uma maneira de compreender esta faculdade humana. Em tempo, é preciso expor que entendemos a linguagem humana não como uma designação do mundo, mas, antes, como um atestado de relações de significação, demonstração de formas de uso de palavras e frases, além de, sem dúvida, posições ideológicas frente ao mundo e frente à linguagem mesma (BAKHTIN, 1997). Qualquer que seja a língua em foco, portanto, haverá uma maneira de dispor os seus elementos estruturais nos mais diversos contextos de uso. Em se tratando de tradução e de interpretação, por consequência, estaremos tratando de relações discursivas estabelecidas entre falantes de duas línguas, não ocupados em determinar como um ou outro grupo "nomeia" a realidade, mas, antes, preocupados em analisar como tais sujeitos organizam o mundo ao mesmo tempo em que ordenam a linguagem.

É assim que entendemos que o trabalho do TILS, assim como as pesquisas sobre a língua de sinais, tem a responsabilidade de desbravar formas linguísticas para haver uma retroalimentação dessas mesmas pesquisas. Não é desejável e muito menos dotará os surdos de um maior poder sobre suas vidas o fato de atribuir a eles a propriedade sobre a língua de sinais. Isso seria, conforme o exposto acima, criar uma nova forma de logocentrismo, uma nova concepção metafísica dobrada sobre as experiências linguísticas dos surdos. Nesse sentido, a comunidade de falantes da língua de sinais, se compreendida como uma coletividade livre de dicotomias definidoras, pode trazer às pesquisas outro tipo de potência, mais livre, mais comprometida e mais interessante. 


\section{Notas}

1. Entendemos que a sala de aula, principalmente no contexto de pós-graduação, sugere uma atuação do TILS em que a separação entre tradução e interpretação se torna difusa. Levando em conta a complexidade do trabalho, pela constante preparação/estudo de textos, pela urgência que sentimos, como profissionais, no adentramento aos universos conceituais com que nos deparamos, consideramos que a atividade de tradução/interpretação consiste em um movimento crítico, criador e coletivo que envolve tanto os TILS como os surdos usuários.

2. Um exemplo amplamente polemizado nos últimos anos é a luta por concursos públicos adequados à atuação. Por enquanto esta discussão está limitada ao contexto das universidades federais, cuja exigência dos concursos tem sido na grande maioria o Ensino Médio com certificação em proficiência na tradução e interpretação da Libras. Citamos, inclusive, o I Fórum Nacional de Tradutores e Intérpretes de Libras-Português das Instituições Federais de Ensino, evento realizado em Florianópolis/SC em 2014 que teve como intuito nortear as demandas dessas instituições, sendo que, evidentemente, a principal delas é a redesignação dos cargos de Tradutor e Intérprete de Língua de Sinais. O objetivo é que, futuramente, todos os concursos passem a exigir a formação em nível superior.

\section{Referências}

ARROJO, Rosemary. Tradução, Desconstrução e Psicanálise. Rio de Janeiro: Imago, 1993.

BAKHTIN, M. Marxismo e filosofia da linguagem. Tradução de Michel Lahud e Yara Frateschi Vieira. 8 ed. São Paulo: Hucitec, 1997.

BARTHES, Roland. A morte do autor. In: O rumor da Língua. Prefácio Leyla 
Perrone-Moisés; tradução Mário Laranjeira. São Paulo: Martins Fontes, 2004. 57-64.

BENJAMIN, Walter. Escritos sobre mito e linguagem 1915-1921. São Paulo: Editora 34; Duas Cidades, 2011.

BRASIL. Decreto $n^{o}$ 5.626, publicado no D.O.U. em 22 de dezembro de 2005. Regulamenta a Lei $n^{\circ} 10.436$, de 24 de abril de 2002, que dispõe sobre a Língua Brasileira de Sinais - Libras, e o art. 18 da Lei $\mathrm{n}^{0} 10.098$, de 19 de dezembro de 2000 .

CANDIOTTO, Cesar. Notas sobre a arqueologia de Foucault em "As palavras e as coisas”. Rev. Filosofia, Aurora, Curitiba, v. 21, n. 28, p. 13-28, jan./jun. 2009.

DERRIDA, Jacques; ROUDINESCO, Elizabeth. De que amanhã... diálogos. Trad. André Telles. Rio de Janeiro: Jorge Zahar Editor, 2004.

DERRIDA, Jacques. A Estrutura, o Signo e o Jogo no Discurso das Ciências Humanas. In: A Escritura e a Diferença. São Paulo: Perspectiva, 1971, p. 229-249.

. Gramatologia. Trad. Miriam Chnaiderman e Renato Janine Ribeiro. São Paulo: Perspectiva, 2004.

. O olho da universidade. Trad. Ricardo Iuri Canko e Ignacio Antonio Neis. São Paulo: Estação Liberdade, 1999.

. Torres de Babel. Trad. de Junia Barreto. Belo Horizonte: Editora $\overline{\mathrm{UFMG}}, 2002$.

FISH, Stanley. Is there a text in this class? Cambridge - Harvard University Press, 1980.

FOUCAULT, Michel. As palavras e as coisas. Tradução de Salma Tannus Muchail. 8. ed. São Paulo: Martins Fontes, 1999. 
NIETZSCHE, Friedrich. Genealogia da moral: uma polêmica. Tradução, notas e posfácio Paulo César de Souza. São Paulo: Companhia das Letras, 2009.

PEREIRA, Maria Cristina Pires. Testagem Linguística em Língua de Sinais: as possibilidades para os intérpretes de Libras. Dissertação (mestrado em Linguística Aplicada) Universidade do Vale do Rio dos Sinos. 2008. 180p.

REICHERT, André Ribeiro. Intérpretes, Surdos e negociações culturais. (Tradução de Luiz Daniel Rodrigues). In: Um olhar sobre nós surdos: leituras contemporâneas/ Gládis Perlin, Marianne Stumpf (Org.). Curitiba: CRV, 2012.

RUSSO, Ângela. Intérprete de língua brasileira de sinais: uma posição discursiva em construção. Dissertação (mestrado em Educação) Universidade Federal do Rio Grande do Sul. 2010. 130p.

SANTOS, Silvana Aguiar. Tradução e interpretação de língua de sinais: deslocamentos nos processos de formação. Cadernos de Tradução, v. 2, p. 145-164, 2010.

. Tradução/interpretação de língua de sinais no Brasil: uma análise das teses e dissertações de 1990 a 2010. Tese (Doutorado em Estudos da Tradução) Universidade Federal de Santa Catarina. 2013. 313p.

WITTGENSTEIN, Ludwig. Investigações Filosóficas. Tradução: José Carlos Bruni. São Paulo: Editora Nova Cultural, 1999.

Recebido em: 30/06/2015 Aceito em: 30/09/2015 